\title{
Mechanical Properties of Concrete with partial replacement of Coarse aggregates by Coconut Shells and reinforced with Coconut Fibre
}

\author{
Mandal B. ${ }^{1}$, Tiwari S. ${ }^{1}{ }^{*}$, Ghimire S. ${ }^{1}$, Tiwari A. ${ }^{2}$
}

1 Department Of Civil Engineering, Pulchowk Campus, Institute of Engineering, Tribhuvan University, Pulchowk, Lalitpur, Nepal

2 Structural Engineer,National Society for Earthquake Technology - Nepal (NSET), Nepal

* Corresponding Author: tiwarisushant78@gmail.com

Received: 16-09-2018

Revised: 01-12-2018

Accepted: 18-12-2018

\begin{abstract}
This paper centers around the study of physical and mechanical properties of concrete reinforced with coconut fibre and the coarse aggregates of which are partially replaced with coconut shells. American Concrete Institute (ACI) method has been used to design M20 concrete wherein coconut shells (CS) replaced the coarse aggregates (CA) by 6\%, $8 \%, 10 \%, 12 \%$ and $14 \%$ by volume. Under each replacement of CA by CS, coconut fibres were added by $3 \%, 4 \%$ and $5 \%$ of cement content. Compressive strength of concrete was found to comply with characteristic strength for certain mixes which avers that the replacements were justifiable for concrete production and thus, the optimum mix for the concrete prepared thereby, would have to be considered accentuating the tensile strength which was actually the one with $10 \%$ replacement of CA by CS in terms of volume and $3 \%$ addition of coconut fibre. The research vividly evinces a decrease in overall density of the concrete thus prepared. The authors suggest the use of coconut shell and fibre in the production of concrete not only because they impart themselves as viable materials, but their use would also assist to abate the amount of environmental waste.
\end{abstract}

Key words: coconut shell, coconut fibre, mechanical properties, non-conventional aggregate, concrete.

\section{Introduction}

Pertaining to the massive growth in construction industry parallel to growth in population, the use of concrete has been escalating in various forms for infrastructure development. This assert that concrete is the $2^{\text {nd }}$ most consumed material on earth after water and estimate that around 7.23 billion tons of concrete is produced every year (Aggregate Industries, H \& S Department, 2008). For developing economies like Nepal, wherein infrastructure development calls for massive investments the use of concrete is certainly going to upsurge in the following years.

Concrete is a composite material abode of aggregates, cement and water held together to form a solid, strong mass that has been used as a robust construction material associating to its remarkable compressive strength, shear strength and pre-stressing properties. Another significant advantage of concrete as a construction material is its ability to take in other materials which can be used to enhance the overall performance or result in decrease of cost related to production. A significant proportion of concrete is aggregate of which makes up 66-78 percentage of total volume. (Vishwas \& Sanjay, 2013). The design of concrete is basically about deducing the relative proportion of different constituents as variation in proportion of constituents causes difference in strength and performance. A number of authors have employed this attribute of concrete to study the effect of replacement of conventional coarse aggregates with materials like palm shells and coconut shells on the strength and durability of concrete. However, the materials to be used for replacement must be pertinent to the function that they are expected to endow. On the grounds of literature study, the authors have used Coconut Shell (CS) as suitable material for partial replacement of coarse aggregate in concrete 
which helps not only in economic production of concrete but also in the management of solid waste (Gunasekaran et al., 2011). In addition, coconut shell fibers (CF) have been added to ameliorate the tensile and flexural property of concrete (Ahirwar \& Joshi, 2015).

Light Weight Concrete (LWC) has procured remarkable attraction in the construction industry attributing to its features like lower density, lower self-weight and lesser foundation costs. Besides, LWC is admired not only for the aforementioned properties but also for the abatement of disposal of agricultural solid waste like the CS which could be used as light weight aggregate for the production of LWC. Thus, LWC is relevant not only for structural reasons but also in the view of curtailing environmental problems. Although a number of research have already been conducted on CS concrete and concrete reinforced with coconut fibres (CRCF) individually, the authors conducted a study using both the materials to observe how they deviated the physical properties of concrete from conventional concrete.

For a nation like Nepal situated in a highly seismic region, with a number of estimates available (Center for Disaster Management and Risk Reduction Technology, 2015) to expound the damage that earthquakes can inflict, it is intrinsic to study methods to optimize the performance of buildings among which the use of lightweight concrete to reduce the dead load of concrete structures which consequently leads to reduction in seismic forces can be a prominent option.

Objectives:

i. $\quad$ To study the combined effect of use of the CS as aggregate and CF as reinforcing material in the physical and mechanical properties of concrete.

ii. To assess the optimum proportion of CS and CF for strength.

iii. To determine the decrease in density of concrete due to replacement of aggregate by CS.

\section{Literature Review}

Concrete as a construction material has a peculiar property that its properties can be altered as per requirement adding various other ingredients. Even for the traditional concrete, its intrinsic properties like workability, colour, setting time can be changed by varying its constituents. However, researchers have been looking for materials other than conventional materials, literally, using agricultural wastes for production of concrete (Mannan \& Ganapathy, 2004; Mannan \& Ganapathy, 2002; Olanipekun et al., 2006; Alengaram et al., 2008) as they also contribute significantly in utilizing what could degrade environmental quality into construction material.

Olanipekun et al. (2006) investigated the comparative cost and strength of concrete produced using coconut shell and palm kernel shells as substitutes for coarse aggregates and concluded that concrete produced using coconut shell has better compressive strength though palm kernel shells are quite cheaper. However, the use of both these shells renders cheaper production with respect to conventional concrete. The strength to economy ratio establishes coconut shell over palm kernel shells as a suitable substitute for conventional coarse aggregate.

Chanap (2012) enlist the following properties of coconut shell which make it suitable to be used as coarse aggregate for concrete:

- High Lignin Content that makes it more weather resistant

- Low cellulose content which causes it to absorb less moisture as compared to other agricultural waste.

- Non-biodegradable 
- Sugar in the coconut shell is not in a free sugar form because of which it has no effect on setting time and the strength of concrete.

- High strength and modulus properties.

- Surface texture is smooth on concave and rough on convex surface.

Kanojia \& Jain (2017) observed the effect of partial replacement of coconut shell as coarse aggregate in concrete and assessed the additional quantity of cement required to be added to account for the strength loss due to replacement. They designed the conventional concrete first without replacement and started replacement of coarse aggregate with coconut shells by volume of $10 \%, 20 \%, 30 \%$ and $40 \%$. In the next part, varying the proportions of coarse aggregate and coconut shells were taken and three different water-cement $(\mathrm{w} / \mathrm{c})$ ratio were considered and finally the $\mathrm{w} / \mathrm{c}$ ratio for target strength was determined. They concluded that $\mathrm{w} / \mathrm{c}$ ratio has to be reduced to get the required strength for increasing quantity of coconut shell. Further, they also present that the density decreases by $7.5 \%$ for replacement by $40 \%$. Another major conclusion of this research was that no additional cement was required for $5 \%$ replacement of coarse aggregates and $3.6 \%$ additional cement is required for $10 \%$ replacement.

Basri et al. (1999) depicted that wood based materials would not contaminate or leach to produce toxic substances once they are inserted in the concrete matrix as they are hard and have organic nature (Basri et al., 1999).

Gunasekaran et al. (2011) studied the compressive, flexural, splitting tensile strength, impact resistance and bond strength of the coconut shell concrete. This research suggests the cement content under replacement that is required to meet the criteria of structural LWC as per ASTM, (minimum 28-days compressive strength should not be less than $17 \mathrm{~N} / \mathrm{mm}^{2}$ ). The authors also mention that individual shell strength plays an important role in the overall strength of concrete as they observed the breakage of CS aggregates. Finally, the authors also conclude that CS endows better workability because of smooth surface on one side of shells.

Gunasekaran et al. (2012) mention that CS has higher water absorption value of around 24\% compared to other conventional aggregate. Thus, to prevent water absorption CS shells are to be used in saturated surface dry condition by immersing in water for 24 hours.

Nagathan et al. (2016) conclude that coconut shells exhibit more resistance against crushing and impact with respect to crushed granite aggregate.

Gunasekaran et al. (2013) conducted a study on reinforced lightweight coconut shell concrete beam under flexure and in 2014 Gunasekaran et al. (2014) they conducted another study on reinforced lightweight coconut shell concrete beam behavior under torsion.

Ali et al. (2012) cited the work of Munawar et al. (2007). which mentions coconut fibre is the toughest among all fibre and are capable of taking strain 4-6 times more than that of other natural fibres.

(Ramakrishna \& Sundararajan, 2005) investigated the loss of tensile strength for four fibers, namely coconut, sisal, jute and hibiscus cannabinus by alternate wetting and drying as well as continuous immersion for 60 days in water, saturated lime and sodium hydroxide and reported that it resulted in chemical composition of all fibres. They also suggest that continuous immersion lead to considerable loss of tensile strength and that coconut fibers were better in regard that they retained tensile strength better than other fibres.

Two types of coconut fibres are available namely brown fibre obtained from matured coconut shell and white fibre obtained from immature coconut shell. Brown fibre being thick and strong unlike the weaker and smooth white fibre are mostly used for engineering purposes. Ali et al. (2012). This research actually centered around the comparison on static and dynamic moduli of coconut fibre reinforced concrete (CFRC) for fibre content 1\%, 2\%,3\% and $5 \%$ of cement 
content and fibre lengths of $2.5 \mathrm{~cm}, 5 \mathrm{~cm}$ and $7.5 \mathrm{~cm}$ and suggested that CFRC with a fibre length of $5 \mathrm{~cm}$ and fibre content of $5 \%$ has the best properties.

Aziz et al. (1981) studied the properties of cement paste for varying lengths of coconut fibres and varying fraction of volume. The research demonstrated that highest mechanical properties were for $4 \%$ volume fraction and under $4 \%$ volume fraction itself they conducted tests on tensile strength for varying lengths of coconut fibres and reported that the optimum strength was for a length of $38 \mathrm{~mm}$. Thus, coconut fibres with $4 \%$ volume fraction and $38 \mathrm{~mm}$ length resulted in optimum properties of cement paste.

John et al. (2005) studied the durability of coconut fibres in cement composites, whereby fibre reinforced alkaline cement mortar were taken from internal and external wall of a building 12 years old. The difference in lignin content from the internal and external wall was found to be inconsiderable.

Sivaraja et al. (2010) conducted tests on CFRC at an interval of 3 months for 2 years under alternate wetting and dry conditions after the specimens were cured for 28 days. Comparing the compressive strength, splitting tensile strength and the modulus of rupture, all these properties escalated in magnitude parallel to the age which explicated the durability of fibres.

Filho et al. (2000) recommend that washed and boiled fibres effectively increase the fibre matrix bond strength. It was shown that in comparison to fibres without pre-treatment the internal bond between washed and boiled fibres and the cement paste is doubled.

Compared to chemical treatment soaked fibres have higher tensile strength and strain and in comparison to soaked fibres boiled fibres have still better results. Boiled fibres have improved bond strength by $184 \%$ compared to soaked fibres.

\section{Methodology}

The literature review on coconut shell vividly elucidates that coconut shells can be adopted as replacement for conventional coarse aggregates but since the overall strength of concrete depends on properties of shells they need to be studied in detail.

The determination of combined effects, on concrete due to partial replacement of CA with CS and reinforced with CF is involved destructive testing. Thus, cubes of $100 \mathrm{~mm} * 100 \mathrm{~mm} * 100 \mathrm{~mm}$ were used for determining the compressive strength and cylinder of $100 \mathrm{~mm}$ diameter and $200 \mathrm{~mm}$ height for the determination of splitting tensile strength of concrete thus produced.

The methodology can be briefly articulated in the following points:

i. Coconut shells were washed and dried for 30 days. They were used in saturated surface dry condition in the concrete mix.

ii. Coconut shell fibres were extracted from the coconut shells and treated by boiling them for around 2 hours. The fibres were cut into lengths of $4 \mathrm{~cm}$.

iii. M20 concrete as per ACI method was designed wherein CA was replaced by CS by $6 \%, 8 \%, 10 \%, 12 \%$ and $14 \%$ in terms of volume. Within each replacement of CS by volume, fibres in amount representing $3 \%, 4 \%$ and $5 \%$ of cement content were added. Thus, the deviation of concrete produced using replacements from conventional concrete were studied.

iv. Also, the optimum mix for strength was determined. Those mix which yielded to characteristic strength were only considered.

v. A total of 144 cubes and 144 cylinders were prepared for the aforementioned purpose.

vi. The cubes and cylinders were subjected to a controlled curing. 
vii. The cubes and cylinders were subjected to compressive test and splitting test respectively at 7 days, 28 days and 60 days to study the growth in strength.

viii. The specimens were weighed under air dry condition to study the density of concrete and decrease in density due to replacement.

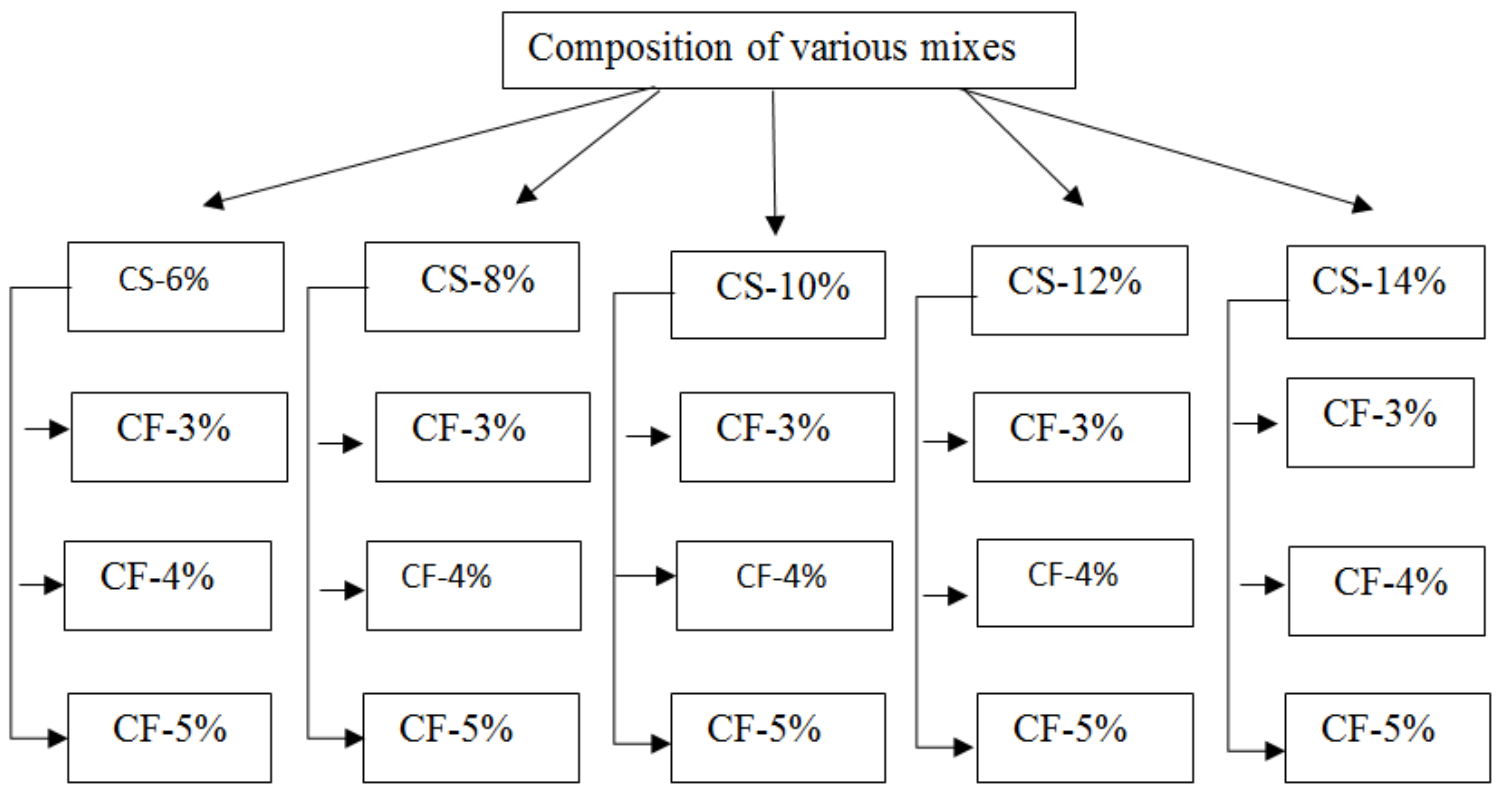

Chart 1. Various possible mixes of CS and CF

\section{Materials used}

The basic ingredients of concrete that were used were:

\section{a. 43 grade PPC cement}

The use of PPC cement can be justified from the fact that it enhances the durability of concrete in regions of significant chloride and sulphate attacks. The specific gravity of cement is taken to be 3.15 .

\section{b. Coarse and Fine aggregates}

Table 1. Properties of Aggregates

\begin{tabular}{|c|c|c|}
\hline S.N & PROPERTIES & VALUE \\
\hline \hline \multicolumn{3}{|c|}{ COARSE AGGREGATE } \\
\hline 1 & Fineness modulus & 4.33 \\
\hline 2 & Nominal Size & $20 \mathrm{~mm}$ \\
\hline 3 & $\begin{array}{c}\text { Aggregate Crushing } \\
\text { Value }\end{array}$ \\
\hline 4 & Density & $1650 \mathrm{~kg} / \mathrm{m}^{3}$ \\
\hline \multicolumn{3}{|c|}{ FINE AGGREGATE } \\
\hline 1 & Fineness modulus \\
\hline
\end{tabular}

\section{c. Coconut Shells}

The coconut shells that were used for partial replacement of coarse aggregate in concrete had the following properties. These shells were collected from the vendors around the temples in 
Kathmandu where coconuts are used in large quantities for religious purpose and the shells are openly disposed after use.

Table 2. Properties of Coconut shell

\begin{tabular}{|c|c|c|}
\hline S.N & Physical and mechanical properties & Values \\
\hline \hline 1 & Maximum Size & $15 \mathrm{~mm}$ \\
\hline 2 & Moisture content & $4.51 \%$ \\
\hline 3 & Water Absorption & $18.62 \%$ \\
\hline 4 & Specific Gravity & $1.05-1.20$ \\
\hline 5 & Sat Surface Dry Sp. Gravity & 1.4 \\
\hline 6 & Impact Value & $6.77 \%$ \\
\hline 7 & Abrasion & $2.10 \%$ \\
\hline 8 & Crushing Strength & $1.98 \%$ \\
\hline 9 & Bulk Density & 690 \\
\hline 10 & Fineness Modulus & $7.10 \%$ \\
\hline 11 & Thickness of 10 shell & $4.0-7.0$ \\
\hline 12 & Shape & flaky \\
\hline 13 & Surface Texture & smooth in inner surface and rough \\
& & outer surface \\
\hline
\end{tabular}

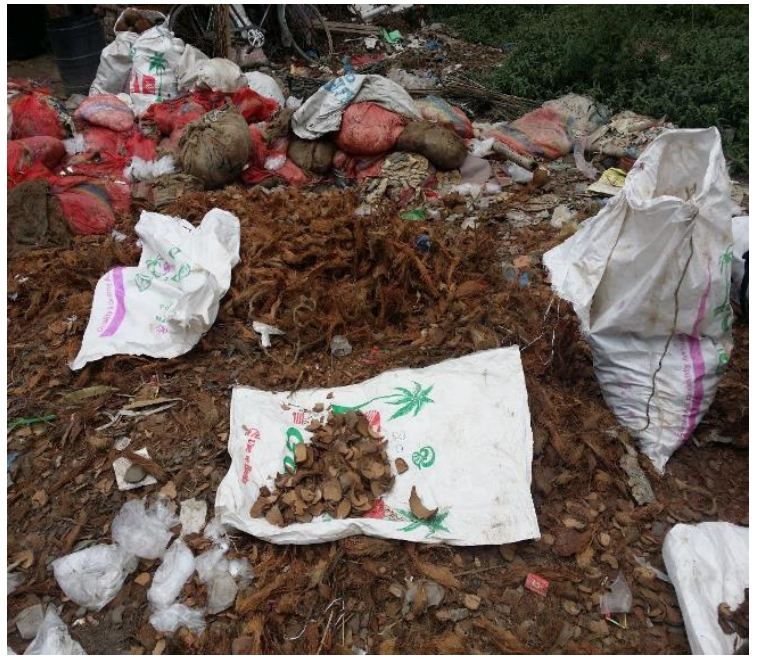

Fig 1. Dumping of Waste Coconut Shells.

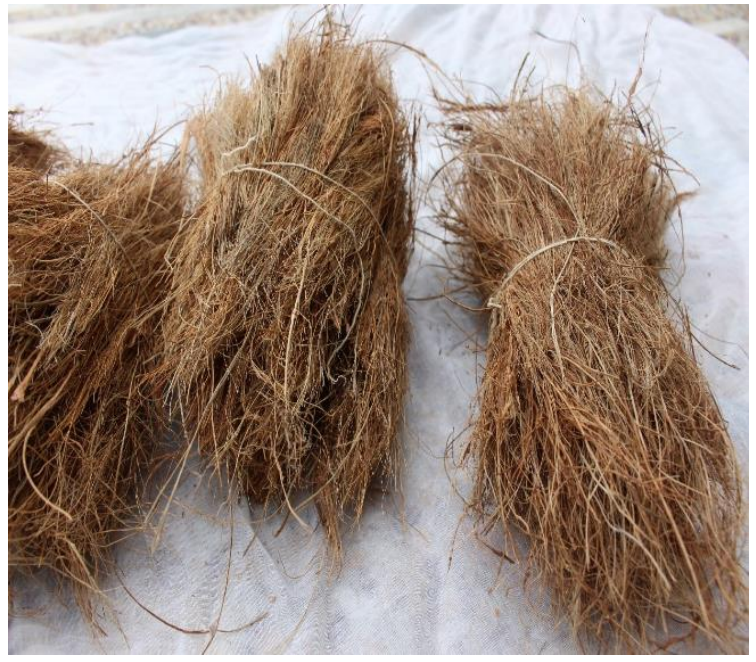

Fig 2. Preparation of Coconut Fibre.

\section{Tests Performed}

\subsection{Compressive strength test}

Compressive strength tests were performed on cubes of dimension $100 \mathrm{~mm}($ IS, 1959) at a loading rate of $150 \mathrm{kN} /$ minute. 3 cubes were tested for each mix and each age. The value of compressive strength is finally, taken as the average compressive strength of 3 cubes. However, the compressive strength of that cube, was discarded which varied significantly, precisely, by more than $20 \%$, from the mean of the other two cube strength values which were close to each other.

\subsection{Splitting Tensile Strength}

The splitting tensile strength tests were performed on cylinders of dimension $100 \mathrm{~mm}$ diameter and $200 \mathrm{~mm}$ height (C 496/C 496M - 04, 1996) at a loading rate of $120 \mathrm{KN} / \mathrm{minute}$. Min et al. (2014) showed that there is increase in strength by $15 \%$ for each unit increase in loading rates 
in $\mathrm{kN} / \mathrm{s}$. Considering this the strength of cylinder should be divided by the factors of 1.2. Three cylinders were tested for each mix and each age. The same method for taking the average as that described for compressive strength was used.

\section{Results and Discussions}

\subsection{Compressive Strength}

The results for the compressive strength test for different mix for 7 days are represented in the following table which elucidates the strength obtained from the compression test on cubes with various contents of shell and fibres at 7 days, 28 days and 60 days. The table also shows clearly, the strength variation at different fibre content for same fraction volume of CS.

Table 3. Variation of Compressive Strength with variation in CS and CF

\begin{tabular}{|c|c|c|c|c|c|c|c|c|c|c|c|c|c|c|c|c|}
\hline & & \multicolumn{5}{|c|}{7 days(MPa) } & \multicolumn{5}{|c|}{28 days (MPa) } & \multicolumn{5}{|c|}{60 days(MPa) } \\
\hline & $\mathrm{CS} \%$ & $6 \%$ & $8 \%$ & $10 \%$ & $12 \%$ & $14 \%$ & $6 \%$ & $8 \%$ & $10 \%$ & $12 \%$ & $14 \%$ & $6 \%$ & $8 \%$ & $10 \%$ & $12 \%$ & $14 \%$ \\
\hline$\circ$ & $3 \%$ & 14.5 & 15.2 & 16.8 & 14.9 & 14.6 & 17.2 & 18.0 & 20.1 & 19.9 & 18.6 & 19.1 & 20.3 & 21.3 & 20.7 & 19.6 \\
\hline 甩 & $4 \%$ & 16.8 & 16.8 & 18.2 & 16.2 & 15.9 & 19.6 & 20.0 & 22.1 & 21.6 & 20.0 & 21.6 & 22.0 & 22.5 & 22.2 & 21.1 \\
\hline u & $5 \%$ & 14.2 & 14.3 & 15.4 & 15.3 & 14.9 & 19.2 & 19.6 & 20.9 & 20.6 & 19.6 & 21.1 & 21.6 & 22.0 & 21.4 & 20.3 \\
\hline
\end{tabular}

It can be clearly observed from the table that 7 out of 15 mixes meet the characteristic strength of $20 \mathrm{MPa}$ at 28 days.

Meticulous observation reveals that for all the mixes, under 28 days strength, addition of fibre by $4 \%$ of the cement content yields the best results which indeed substantializes the findings of Aziz et al. (1981). Thus, taking 4\% addition of fibre as reference, a clear trend of increase up to $10 \%$ replacement of CA by CS in terms of volume can be observed while with further replacement in terms of magnitude leads to reduction in strength. Thus, considering 28 days strength, the best results are obtained at the mix when, CA is replaced in terms of volume by CS by $10 \%$ and fibre is added by $4 \%$ of the cement content in terms of mass. Also, for $10 \%$ replacement by CS, all CF additions meet the characteristic strength.

However, even for $12 \%$ replacement of CA by CS shows that the characteristic strength has been adequately exceeded for $4 \%$ and $5 \%$ addition of fibre, which is even more economical. Thus, with $12 \%$ replacement of CA by CS and addition of CF by $4 \%$ or $5 \%$ is justifiable both in terms of strength and economy. The calculations for $1 \mathrm{~m}^{3}$ of concrete shows that $10 \%$ replacement of CA by CS results in $2.11 \%$ economical mix while for $12 \%$ replacement with CS the mix is $2.53 \%$ economical for Nepalese rates of price for materials.

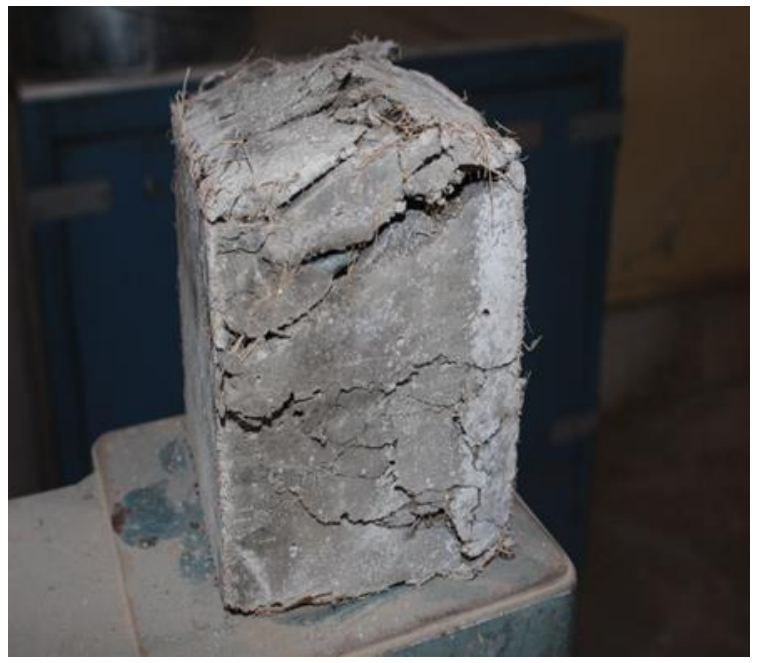

Fig 3. Test for Compressive Strength of Concrete 
Moreover, the average compressive strength has been growing with age for 60 days as illustrated by the table on the basis of which it can be mentioned that the shells and fibres do not undergo decomposition as they are inserted in the concrete matrix which complies with what has been mentioned by Basri et al. (1999).

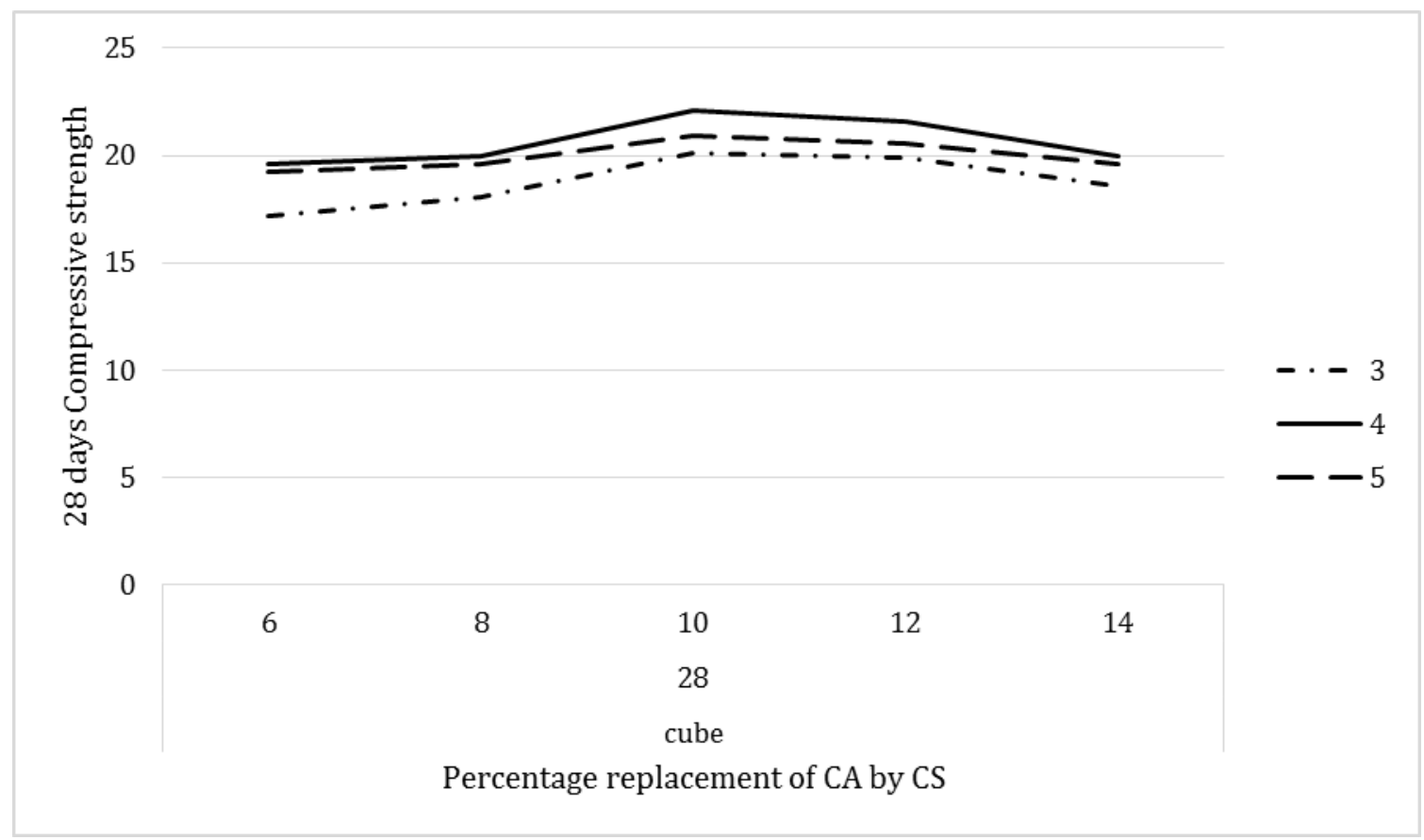

Fig 4. Variation of Compressive Strength with CS and CF.

The above chart illustrates the 28 days compressive strength for all replacements of CA by CS and all addition of fibres under each replacement which shows $10 \%$ CS replacement with 4\% fibre addition as the best mix. The following chart also validates that $4 \%$ addition of fibre yields the maximum strength though after 28 days the increase in strength is at a lower rate than for $5 \%$ additions.

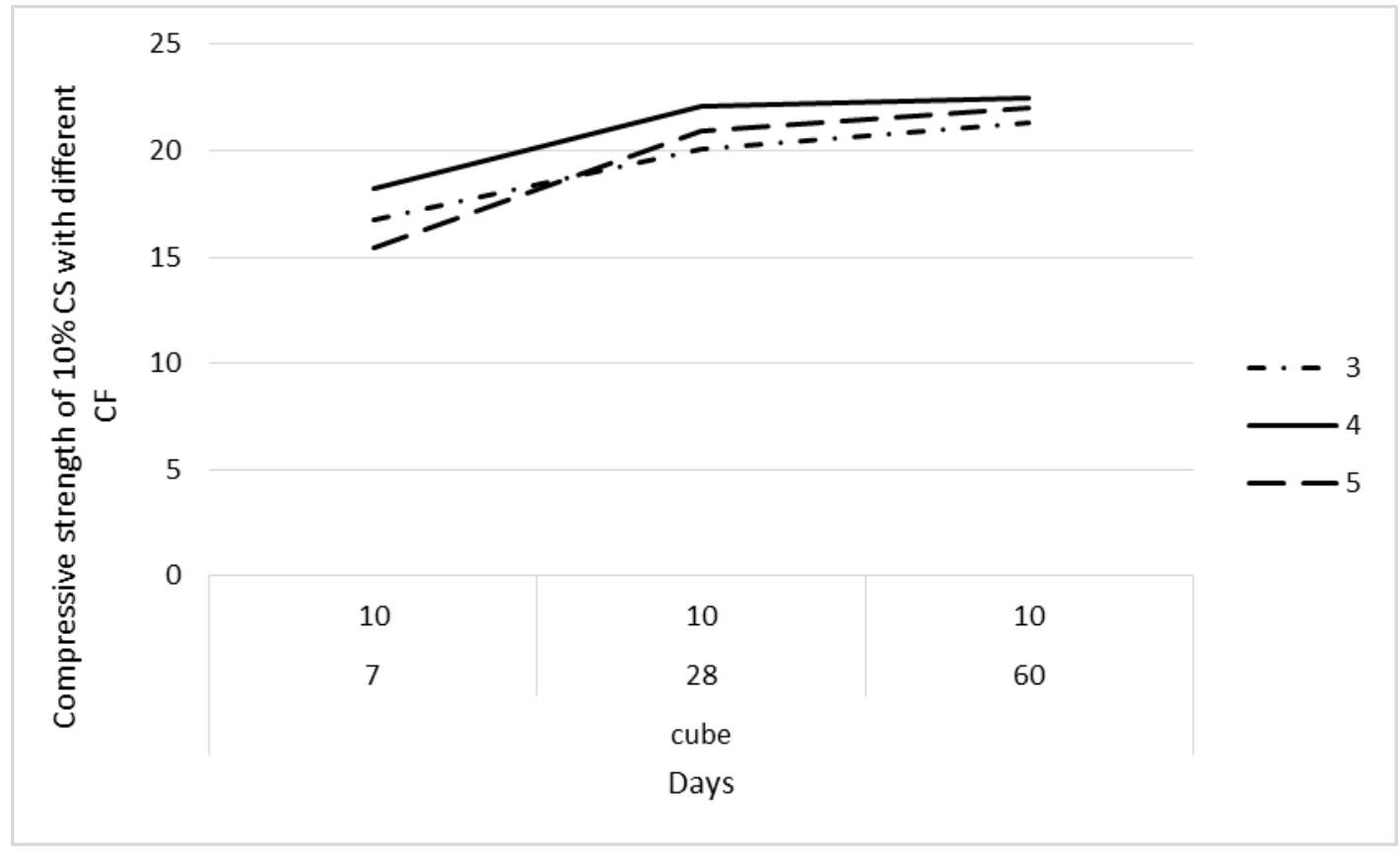

Fig 5. Growth in compressive strength of cube with $10 \%$ CS replacement for all CF with age. 


\subsection{Splitting Tensile Strength}

Table 4. Variation of splitting tensile Strength with variation in CS and CF.

\begin{tabular}{|c|c|c|c|c|c|c|c|c|c|c|c|c|c|c|c|c|}
\hline & & \multicolumn{5}{|c|}{7 days (MPa) } & \multicolumn{5}{|c|}{28 days (MPa) } & \multicolumn{5}{|c|}{60 days (MPa) } \\
\hline & $\mathrm{CS} \%$ & $6 \%$ & $8 \%$ & $10 \%$ & $12 \%$ & $14 \%$ & $6 \%$ & $8 \%$ & $10 \%$ & $12 \%$ & $14 \%$ & $6 \%$ & $8 \%$ & $10 \%$ & $12 \%$ & $14 \%$ \\
\hline \multirow{3}{*}{ 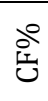 } & $3.00 \%$ & 2.0 & 2.3 & 2.1 & 1.7 & 1.6 & 2.7 & 3.4 & 3.1 & 2.7 & 2.6 & 2.9 & 3.8 & 3.4 & 3.2 & 3.2 \\
\hline & $4.00 \%$ & 2.0 & 2.1 & 1.8 & 1.6 & 1.5 & 3.2 & 3.6 & 3.2 & 3.0 & 3.0 & 2.8 & 3.1 & 3.0 & 2.8 & 3.0 \\
\hline & $5.00 \%$ & 1.8 & 1.8 & 1.8 & 1.9 & 1.8 & 2.9 & 2.6 & 2.8 & 3.1 & 3.1 & 3.1 & 3.0 & 3.2 & 3.3 & 3.2 \\
\hline
\end{tabular}

The 28 days tensile strength showed the best results for $4 \%$ fibre addition for all CS replacements but, all $4 \%$ additions have a decrease in tensile strength at the age of 60 days though they have a higher value of tensile strength compared to conventional M20 concrete. This can be clearly observed in the following charts.

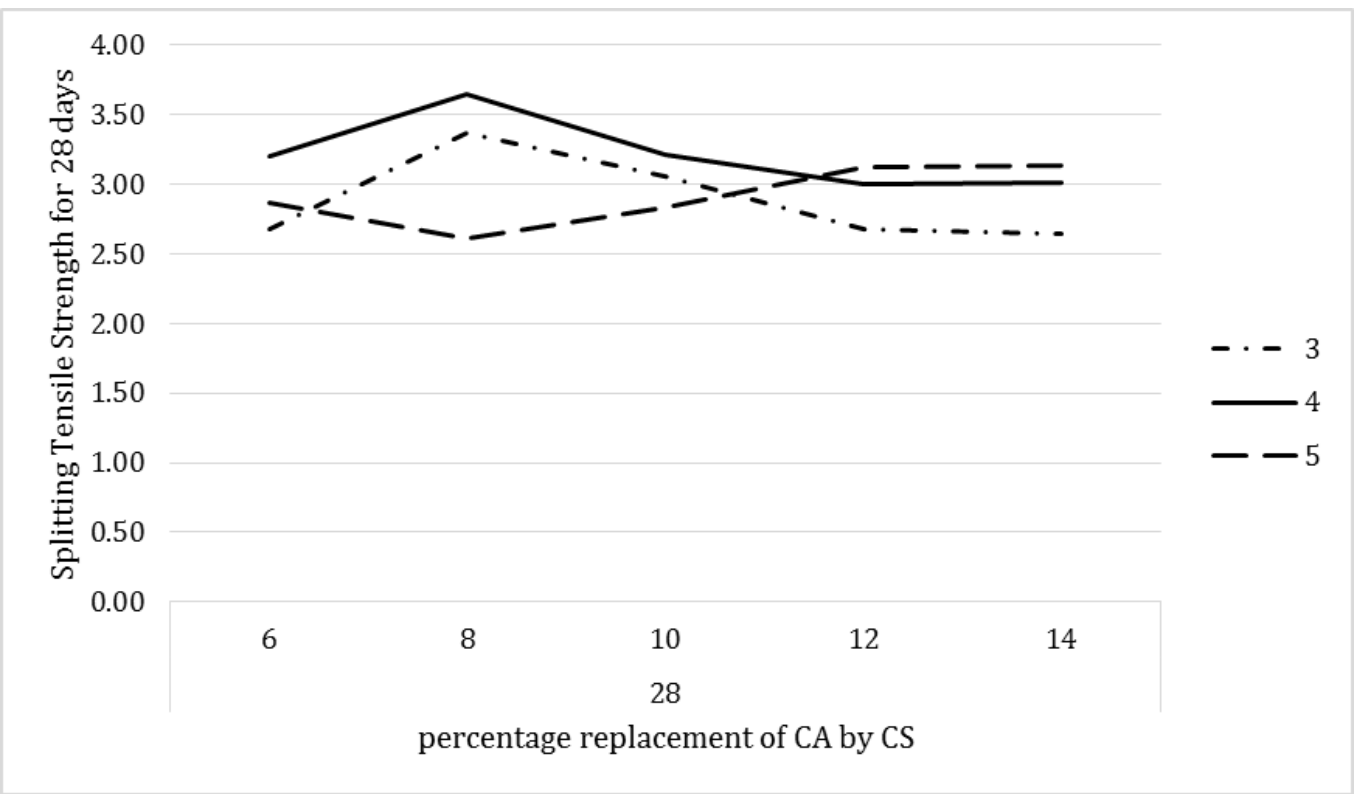

Fig 6. 28 days tensile strength of concrete for all CS replacements.

The above chart shows the highest strength for $8 \%$ replacement of CA by CS and addition of fibre by $4 \%$ of cement mass.

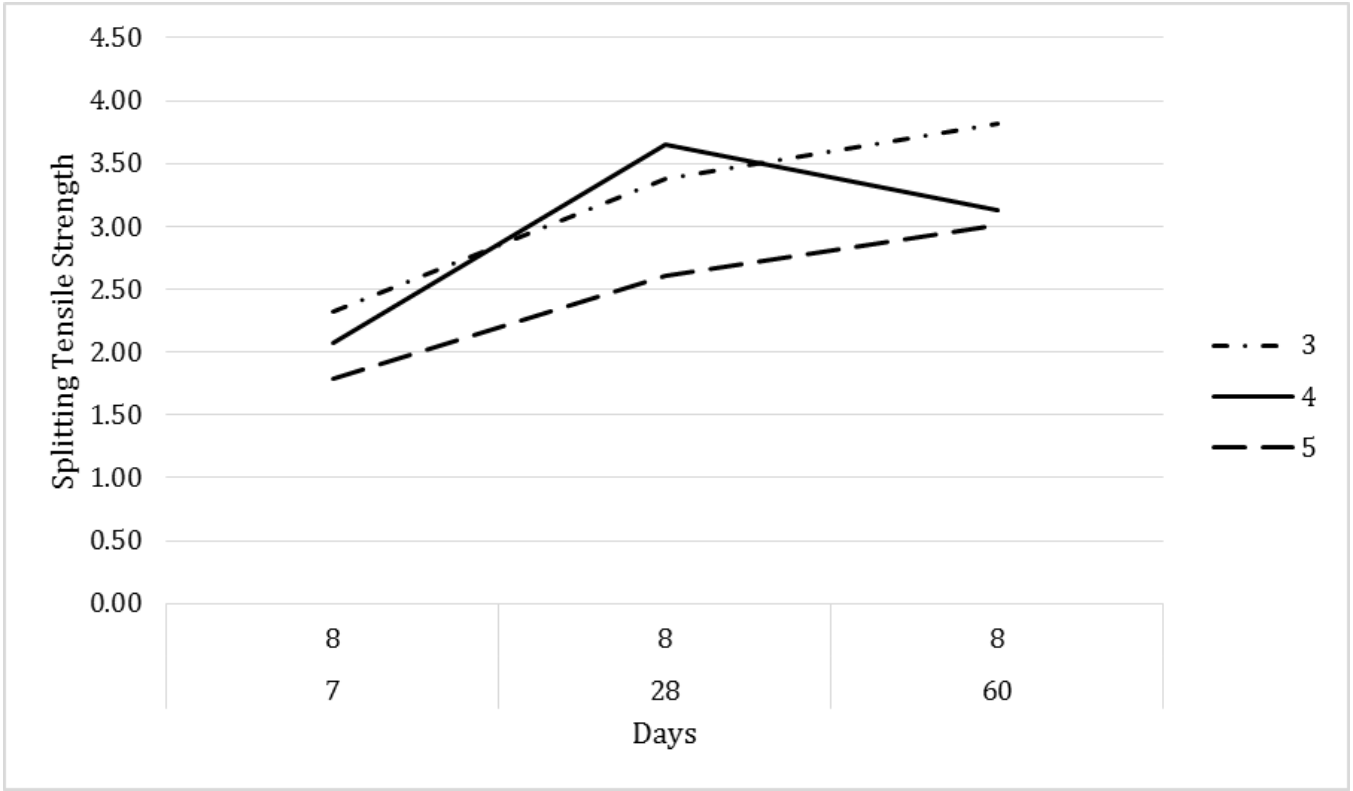

Fig 7. Growth in Tensile strength of Concrete with age for $8 \%$ CS replacement. 
However, the above chart shows that for 28 days the mix with $4 \%$ fibre replacement has the maximum strength but it unknowingly decreases for 60 days that is not the case for other percentage of $\mathrm{CF}$. This behavior of $4 \%$ addition of fibres can be observed not only under $8 \%$ replacement of CA by CS but all other replacements which can be tallied from the table.

Thus, $4 \%$ addition of fibres is unsuitable with regards to splitting tensile strength. Since, the 28 days splitting tensile strength values are exactly equal for $3 \%$ addition of CF under $10 \%$ replacement by $\mathrm{CS}$ and $5 \%$ addition of $\mathrm{CF}$ under $12 \%$ replacement by $\mathrm{CS}$, the best mix for tensile strength is derived from 60 days strength which clearly shows the mix consisting of $10 \%$ replacement of CA with CS and 3\% addition of fibre having the highest tensile strength, the 28 days tensile of strength which is higher than the average value for normal M20 concrete by $30.25 \%$. The tensile strength for normal M20 concrete was found to be $2.38 \mathrm{~N} / \mathrm{mm}^{2}$, which is valid as per Oluokun's (Oluokun, 1991), for relation between tensile strength and compressive strength of concrete. Moreover, the 8\% replacement has not been considered as it does not comply with characteristic compressive strength.

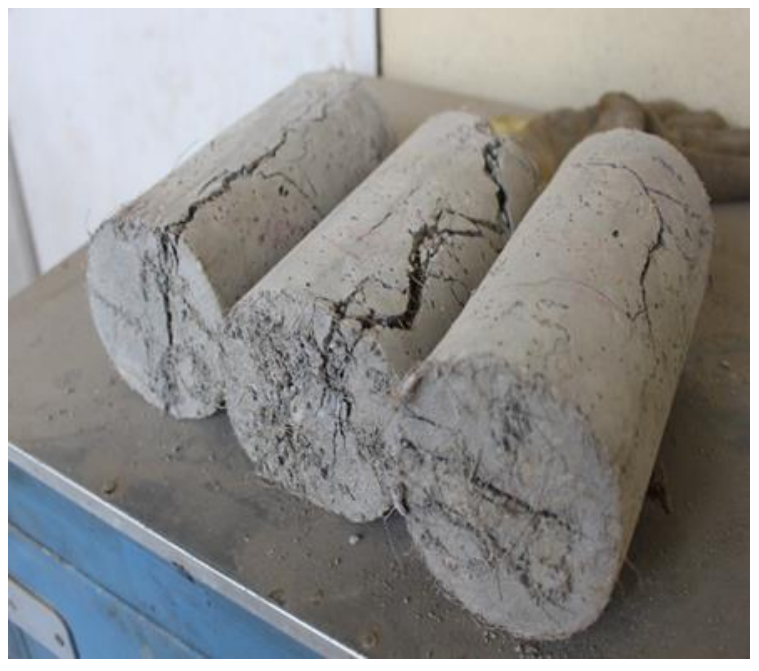

Fig 8. Test for Splitting Tensile Strength of Concrete

The density for normal concrete is $2523 \mathrm{~kg} / \mathrm{m}^{3}$ and the density for the mix of $10 \%$ replacement of CA by CS with $3 \%$ addition of fibres $2248 \mathrm{~kg} / \mathrm{m}^{3}$ which is $10.9 \%$ lighter than normal concrete. (Vishwas \& Sanjay, 2013).

\section{Conclusion}

The replacement of coarse aggregates by coconut shell in concrete along with addition of coconut fibre is justifiable in concrete as it meets the characteristic strength as well as results in increase of tensile strength. The optimum mix for the concrete thus prepared is one with coconut shells replacing coarse aggregates by $10 \%$ by volume along with addition of fibre by $3 \%$ of the cement content. This also results in decrease in density of the concrete. Moreover, during the destructive tests it could be observed that unlike normal concrete the concrete prepared with CS and CF did not undergo brittle failure to which the fibres contributed significantly. The concrete thus prepared not only provides itself as a building material but also helps to abate the environmental problems occurring due to the disposal of coconut waste.

\section{Acknowledgement}

We would like to express our gratitude to the department of Civil Engineering, Institute of Engineering, Pulchowk Campus for providing us with ample workspace, environment and infrastructure for the research. 


\section{References}

Aggregate Industries, H \& S Department, (2008). Safety Data Sheet. Ashbourne, Derbyshire,: Hullandward ward.

Ahirwar, E. A. K., \& Joshi, R. (2015). Experimental Analysis of Fly Ash \& Coir Fiber Mix Cement Concrete for Rigid Pavement. International Journal of Engineering Research and Applications, 5(4), 109-120.

Alengaram, U. J., Jumaat, M. Z., \& Mahmud, H. (2008). Ductility behaviour of reinforced palm kernel shell concrete beams. European Journal of Scientific Research, 23(3), 406-420.

Ali, M., Liu, A., Sou, H., \& Chouw, N. (2012). Mechanical and dynamic properties of coconut fibre reinforced concrete. Construction and Building Materials, 30, 814-825.

Aziz, M. A., Paramasivam, P., \& Lee, S. L. (1981). Prospects for natural fibre reinforced concretes in construction. International Journal of Cement Composites and Lightweight Concrete, 3(2), 123-132.

Basri, H. B., Mannan, M. A., \& Zain, M. F. M. (1999). Concrete using waste oil palm shells as aggregate. Cement and concrete Research, 29(4), 619-622.

C 496/C 496M - 04. (1996). American Society for Testing and Materials, West Conshohocken: ASTM International.

Center for Disaster Management and Risk Reduction Technology. (2015). Nepal Earthquakes - Report \#3. Germany: Institut für Meteorologie und Klimaforschung (IMK-TRO). Retrieved from https://www.cedim.de/download/CEDIM ImpactSummary EarthquakeNepal2015 Report3.pdf

Chanap, R. (2012). Study of Mechanical and Flexural Properties of Coconut Shell Ash, Rourkela: National Institute of Technology, Retrieved from: ethesis.nitrkl.ac.in/3398/1/rahulc_108me033.pdf

Filho, R. D., Scrivener, K., England, G. L., \& Ghavami, K. (2000). Durability of alkali-sensitive sisal and coconut fibres in cement mortar composites. Cement and concrete composites, 22(2), 127-143.

Gunasekaran, K., Annadurai, R., \& Kumar, P. S. (2012). Long term study on compressive and bond strength of coconut shell aggregate concrete. Construction and Building Materials, 28(1), 208-215.

Gunasekaran, K., Annadurai, R., \& Kumar, P. S. (2013). Study on reinforced lightweight coconut shell concrete beam behavior under flexure. Materials \& Design, 46, 157-167.

Gunasekaran, K., Kumar, P. S., \& Lakshmipathy, M. (2011). Mechanical and bond properties of coconut shell concrete. Construction and building materials, 25(1), 92-98.

Gunasekaran, K., Ramasubramani, R., Annadurai, R., \& Chandar, S. P. (2014). Study on reinforced lightweight coconut shell concrete beam behavior under torsion. Materials \& Design, 57, 374-382.

IS. (1959). IS 516-1959. NEW DELHI: BUREAU OF INDIAN STANDARDS.

John, V. M., Cincotto, M. A., Sjöström, C., Agopyan, V., \& Oliveira, C. T. A. (2005). Durability of slag mortar reinforced with coconut fibre. Cement and Concrete Composites, 27(5), 565-574.

Kanojia, A., \& Jain, S. K. (2017). Performance of coconut shell as coarse aggregate in concrete. Construction and Building Materials, 140, 150-156.

Mannan, M. A., \& Ganapathy, C. (2002). Engineering properties of concrete with oil palm shell as coarse aggregate. Construction and Building Materials, 16(1), 29-34.

Mannan, M. A., \& Ganapathy, C. (2004). Concrete from an agricultural waste-oil palm shell (OPS). Building and environment, 39(4), 441-448.

Min, F., Yao, Z., \& Jiang, T. (2014). Experimental and numerical study on tensile strength of concrete under different strain rates. The Scientific World Journal, Article ID 173531, 11 pages.

Munawar, S. S., Umemura, K., \& Kawai, S. (2007). Characterization of the morphological, physical, and mechanical properties of seven nonwood plant fiber bundles. Journal of Wood Science, 53(2), 108113. 
Nagathan, S. J., Jahagirdar, S., Mulla, M., \& Katti, S. (2016). Comparative Study on Coconut Shell Aggregate Concrete with Conventional Concrete. International Journal of Civil and Structural Engineering Research, 4(1), 198-202.

Olanipekun, E. A., Olusola, K. O., \& Ata, O. (2006). A comparative study of concrete properties using coconut shell and palm kernel shell as coarse aggregates. Building and environment, 41(3), 297 301.

Oluokun, F. (1991). Prediction of concrete tensile strength from its compressive strength: an evaluation of existing relations for normal weight concrete. Materials Journal, 88(3), 302-309.

Ramakrishna, G., \& Sundararajan, T. (2005). Studies on the durability of natural fibres and the effect of corroded fibres on the strength of mortar. Cement and Concrete Composites, 27(5), 575-582.

Sivaraja, M., Velmani, N., \& Pillai, M. S. (2010). Study on durability of natural fibre concrete composites using mechanical strength and microstructural properties. Bulletin of Materials Science, 33(6), 719-729.

Vishwas, P. K., \& Sanjay, K. B. G. (2013). Comparative study on coconut shell aggregate with conventional concrete. International Journal of Engineering and Innovative Technology, 2(12), 67-70. 